\title{
Measurement of trace nitrate concentrations in seawater by ion chromatography with valve switching*
}

\author{
DU Juan (杜娟) ${ }^{1,2}$, FA Yun (法芸) $)^{1, * *}$, ZHENG Yue (郑岳) ${ }^{1,3}$, LI Xuebing (李学兵) ${ }^{4}$, \\ DU Fanglin (杜芳林) $)^{2}$, YANG Haiyan (杨海燕 $)^{1}$ \\ ${ }^{1}$ Public Laboratory, Qingdao Institute of Bioenergy and Bioprocess Technology, Chinese Academy of Sciences, Qingdao 266101, \\ China \\ ${ }^{2}$ College of Materials Science and Engineering, Qingdao University of Science \& Technology, Qingdao 266042, China \\ ${ }^{3}$ College of Food Science and Engineering, Shandong Agricultural University, Tai'an 271018, China \\ ${ }^{4}$ Heterogeneous Catalysis Conversion Group, Qingdao Institute of Bioenergy and Bioprocess Technology, Chinese Academy of \\ Sciences, Qingdao 266101, China
}

Received Jul. 1, 2013; accepted in principle Aug. 16, 2013; accepted for publication Sep. 10, 2013

(C) Chinese Society for Oceanology and Limnology, Science Press, and Springer-Verlag Berlin Heidelberg 2014

\begin{abstract}
An ion chromatographic method with a valve switching facility was developed to determine trace nitrate concentrations in seawater using two pumps, two different suppressors, and two columns. A carbohydrate membrane desalter was used to reduce the high concentrations of sodium salts in samples. In this method, trace nitrate was eluted from the concentrator column to the analytical columns, while the matrix flowed to waste. Neither chemical pre-treatment nor sample dilution was required. In the optimized separation conditions, the method showed good linearity $(R>0.99)$ in the 0.05 and $50 \mathrm{mg} / \mathrm{L}$ concentration range, and satisfactory repeatability $(\mathrm{RSD}<5 \%, n=6)$. The limit of detection for nitrate was $0.02 \mathrm{mg} / \mathrm{L}$. Results showed that the valve switching system was suitable and practical for the determination of trace nitrate in seawater.
\end{abstract}

Keyword: ion chromatography; valve switching; seawater; nitrate ion

\section{INTRODUCTION}

Determining trace nitrate concentrations in seawater is very valuable for oceanographic studies (Fukushi et al., 2009). Many methods have been used to determine nitrate concentrations, such as spectrophotometry (Finch et al., 1998; Sastry et al., 2002; Zhu, 2006), gas chromatography (GC) with electron capture detector (ECD) (Walsh, 2001), ion chromatography (IC) coupled with inductively coupled plasma mass spectrometry (ICP-MS) (Bettinelli and Spezia, 1995) and ion chromatography (IC) (Helaleh and Korenaga, 2000). These methods, however, have been used in the absence of a matrix (Walsh, 2001).

IC is the most widely used analytical method to determine ion species (Dahllöf et al., 1997; Geng et al., 2008; Haddad et al., 2008). It is an easy and straightforward way to quantify major anions, such as chloride, in seawater. The determination of trace anions in seawater remains a challenge because of the interference of salt matrices (Wilson et al., 2011). Until now, there have been few studies on the analysis of low-level ions in seawater (Gros, 2013). Huang et al. (2000) described an IC method for determining trace analytes in seawater combined with chloride removal using a pre-concentration technique. However, in this method, the analytical column may block because of colloidal $\mathrm{AgCl}$, which is produced by the co-precipitation or adsorption of analytes, and/ or $\mathrm{Ag}^{+}$release, in the $\mathrm{Ag}^{+}$cartridges used for chloride removal (Haddad and McTaggart, 1991; Slingsby and Pohl, 1996).

\footnotetext{
* Supported by the National Special Fund for Major Research Instrumentation Development (No. 2012YQ090229), the Instrument Functional Exploitation and Technical Innovation Fund, Chinese Academy of Sciences (No. yg2010072), and the Shandong Provincial Technology Development Plan Fund (Nos. 2011SJGZ06, 2012SJGZ12, 2012424012) ** Corresponding author: fayun@qibebt.ac.cn
} 
In recent years, the valve switching technique has been shown to be a powerful analytical tool to deal with matrix interference (Bruno et al., 2003). This technology was previously described as an effective matrix elimination method rather than a sample pretreatment method (Villasenor, 1991), and was not only applied in liquid chromatography (Opiteck et al., 1998; Wang et al., 2009), but also in ion chromatography (Huang et al., 2000; Wang et al., 2012). IC coupled with valve switching has earned a reputation for high sensitivity and automated operation because of its ability to use different stationary phases in different columns to switch and trap target ions, and eliminate matrix interference.

In this study, we developed a valve switching IC method. Trace nitrate was eluted from the concentrator column to the analytical columns, while the bulk of the matrix flowed to waste. Compared with conventional valve switching methods, this method has the advantage of using a much larger capacity suppressor with the ability to exchange more sodium salts in seawater. This means that it can eliminate matrix interference more efficiently. This is in contrast to most of the existing methods, which cannot suppress a sufficiently large quantity of the matrix in small capacity suppressors. Under optimized conditions, the method showed good linearity $(R>0.99)$ in the 0.05 and $50 \mathrm{mg} / \mathrm{L}$ concentration range, and satisfactory repeatability ( $\mathrm{RSD}<5 \%, n=6)$.

\section{METHODOLGY}

\subsection{Instrumentation and chromatography conditions}

The experiment was performed on an ICS-5000 (Thermo Scientific, Waltham, MA, USA) equipped with dual pumps, an auto-sampler, one conductivity detector, two valves (two six-port valves) and a sample loop $(50 \mu \mathrm{L}) .20 \mathrm{mmol} / \mathrm{L}$ sodium hydroxide $(\mathrm{NaOH})$ was manually prepared for primary separation on one Ion Pac AG11-HC guard column (50 $\mathrm{mm} \times 4 \mathrm{~mm}$, Thermo Scientific) and one Ion Pac AS11-HC column $(250 \mathrm{~mm} \times 4 \mathrm{~mm}$, Thermo Scientific), coupled with a Carbohydrate Membrane Desalter CMD $4 \mathrm{~mm}$ (Thermo Scientific). The other Ion Pac AG11-HC guard column $(50 \mathrm{~mm} \times 4 \mathrm{~mm}$, Thermo Scientific) was used as a concentrator column. The $20-\mathrm{mmol} / \mathrm{L}$ potassium hydroxide $(\mathrm{KOH})$ mobile phase was generated by a Reagent-Free Controller (Thermo Scientific). Nitrate was eluted on the concentrator column by an eluent generator, and was separated on the other Ion Pac AS11-HC column
(250 $\mathrm{mm} \times 4 \mathrm{~mm}$, Thermo Scientific) coupled with an ASRS $300(4 \mathrm{~mm})$ (Thermo Scientific). All the instrument control and data acquisition were performed by Chromeleon 6.8 chromatography software (Thermo Scientific). The eluent flow rate was $1.0 \mathrm{~mL} / \mathrm{min}$. The column temperature was $30^{\circ} \mathrm{C}$.

\subsection{Preparation of standards and samples}

All the solutions were prepared using $18 \mathrm{M} \Omega$ water (Millipore, Mosheim, France), and filtered through a $0.22-\mu \mathrm{m}$ nylon membrane filter. Sodium hydroxide $(50 \% \mathrm{w} / \mathrm{w}$, certified grade) was obtained from Acros Organics (Fair Lawn, NJ, USA), and the anion standards were supplied by the National Institute of Metrology, China. Artificial seawater was prepared using sea salts and water. Seawater samples were collected from Jiaozhou Bay (Qingdao, China) and filtered through a membrane filter (pore size $0.22 \mu \mathrm{m}$ ) prior to IC analysis.

\subsection{Experimental procedure}

All the procedures of the system were carried out using valves and pumps interconnected by a narrow poly (ether-ether-ketone) tubing system (Fig.1). Step 1 represents sample loading. Step 2 is the sample injection stage, where chloride is first eluted from column 1 and then eliminated. Step 3 is the extracting phase, in which nitrate is extracted on the trap column. Step 4 involves analysis and re-equilibration, in which nitrate is separated on column 2. Other compounds were eluted to waste from column 1 . Once the system reaches re-equilibration, the cycle restarts from the beginning.

\subsection{Method validation}

The method was validated for precision, linearity and repeatability. Repeatability (the percent of the relative standard deviation) was tested using six $6.0 \mathrm{mg} / \mathrm{L}$ standard replicates. Linearity calibration curves were calculated by plotting the peak areas and concentrations of the external standards. Recovery was determined by $1.0-, 6.0-$, and $10.0-\mathrm{mg} / \mathrm{L}$ spiked standards.

\section{RESULT AND DISCUSSION}

\subsection{The switching window}

We used a standards mixture $(18158 \mathrm{mg} / \mathrm{L}$ chloride and $6.0 \mathrm{mg} / \mathrm{L}$ nitrite) to determine the switching and duration times for valve 2 at which recoveries were 

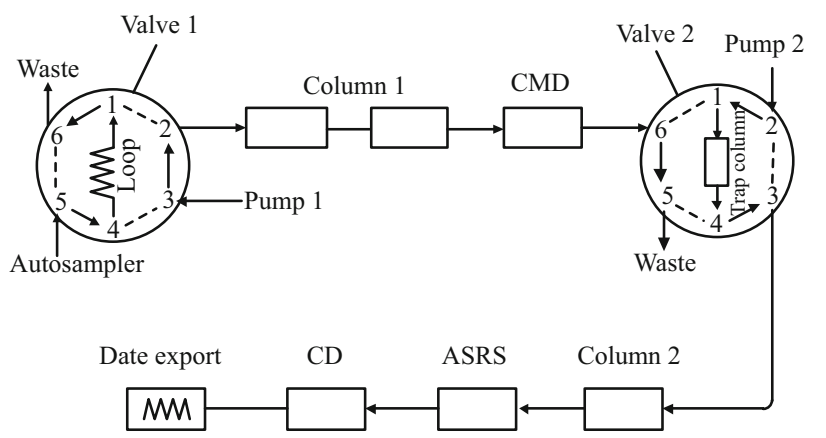

Step 1 Loading sample
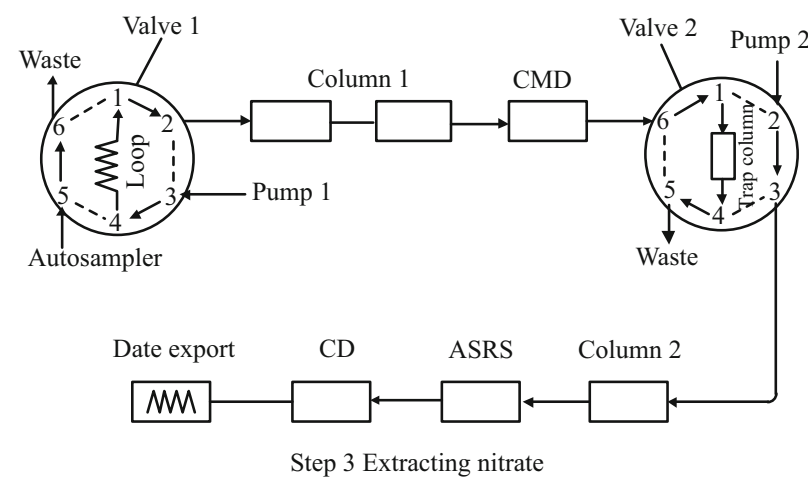
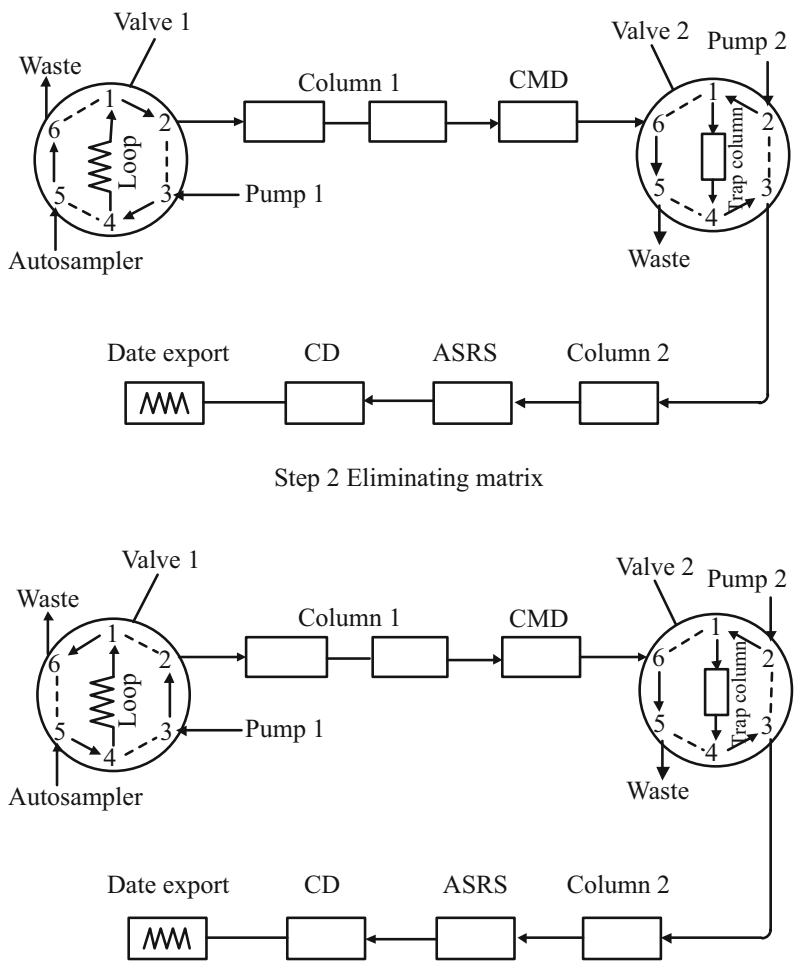

Step 4 Analysis and re-equilibration

Fig.1 System coupled with valve switching

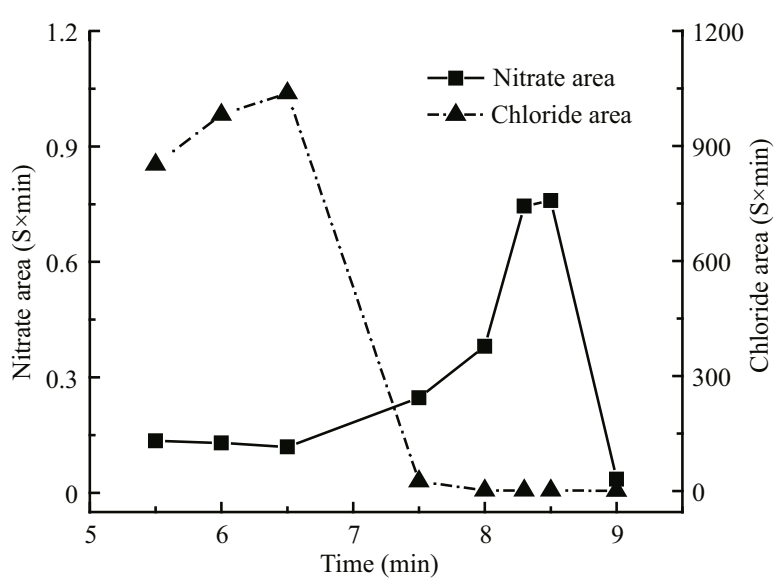

Fig.2 Switching time of valve 2

The black solid line indicates nitrate peak area (left axis); the black short dashed-dot line indicates the chloride peak area (right axis).

highest. As shown in Fig.2, peak chloride occurred between 5.5 and $6.5 \mathrm{~min}$, after which there was a sharp reduction in the peak area, indicating chloride elimination. Nitrate peaked at $8.5 \mathrm{~min}$, which suggests that $8.5 \mathrm{~min}$ was the best time for switching.

The duration time is shown in Fig.3, which indicates a peak value for nitrate at $2.0 \mathrm{~min}$. Therefore, the optimal switching and duration times of valve 2 were $8.5 \mathrm{~min}$ and $2.0 \mathrm{~min}$, respectively. The valve

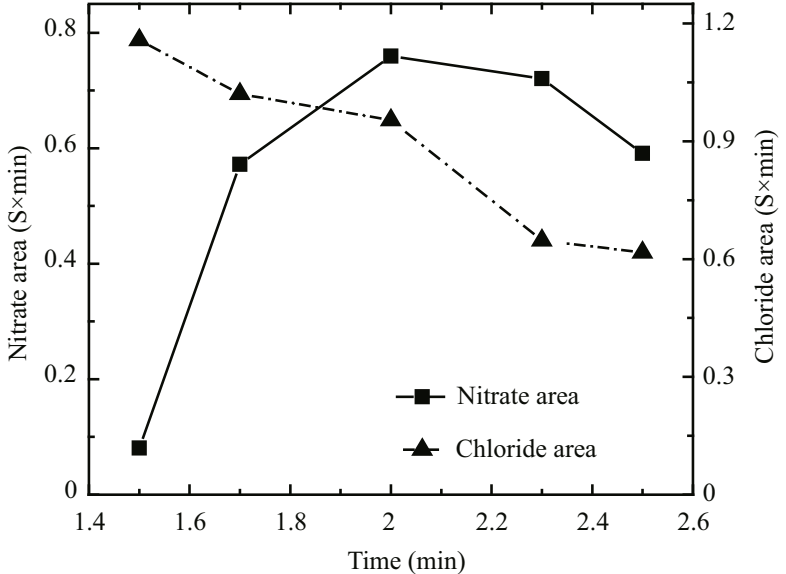

Fig.3 Duration time of valve 2

The solid black line indicates the nitrate peak area (left axis); the short black dashed-dot line indicates the chloride peak area (right axis).

switching procedure is as follows: Step 1 (-4.5$0 \mathrm{~min})$, Step 2 (0-8.5 min), Step $3(8.5-10.5 \mathrm{~min})$ and Step 4 (10.5-30 $\mathrm{min})$.

\subsection{Method validation and sample determination}

This labor-saving technology has provided us with a low cost, automated routine analysis method. This method proved easier to manipulate than using 
Table 1 Reproducibility, correlation coefficient, linear range, limit of detection and average recovery

\begin{tabular}{ccccccc}
\hline Analyte & $\operatorname{RSD}(\%)(n=6)$ & Correlation coefficient $(n=7)$ & Regression equation & Linear range $(\mathrm{mg} / \mathrm{L})$ & LOD $(\mathrm{mg} / \mathrm{L})$ & Average recovery $(\%)$ \\
\hline Nitrate & 4.830 & 0.9992 & $Y=0.1403 X-0.1057$ & $0.05-50$ & 0.02 & 99.2 \\
\hline
\end{tabular}

monolithic ODS columns coated with $5 \mathrm{mmol} / \mathrm{L}$ cetyltrimethylammonium chloride (CTAC) aqueous solution (Ito et al., 2005). The linearity of the response was tested by $50-\mu \mathrm{L}$ injections of standards with the following concentrations: $0.05,0.1,0.5,2,6,10$, and $50 \mathrm{mg} / \mathrm{L}$. Results are given in Table 1 . The LOD of $0.02 \mathrm{ppm}$ for nitrate was lower than that achieved by an alternative column-switching method (Bruno et al., 2003). The correlation coefficient of the calibration reached 0.999 2. Repeatability for the six $6.00 \mathrm{mg} / \mathrm{L}$ standard replicates was $4.83 \%$. The mean recovery for the three replicates of 1.0,6.0, and $10.0 \mathrm{mg} / \mathrm{L}$ spiked standards was $99.2 \%$. The results are more precise than adding a fixed volume of a nitrate standard solution to all the samples (Raessler and Hilke, 2006), because there are no dilution effects.

Trace nitrate in seawater was determined in optimal conditions. The IC chromatogram is displayed in Fig.4, which shows a stable baseline separation without matrix interference. From three replicates, the seawater nitrate concentration was $0.4697 \pm$ $0.001 \mathrm{mg} / \mathrm{L}$.

\section{CONCLUSION}

This study demonstrates that a single valve switching system after injection can be used successfully for the analysis of low-level nitrate. Nitrate and a small amount of chloride were obtained after the initial separation in an analytical column. Low-level nitrate was eluted from the concentrator column to the second analytical column, and the majority of the matrix was eliminated by a large capacity desalter. The proposed method has the potential to become a convenient and practical tool for routine analysis of seawater.

\section{References}

Bettinelli M, Spezia S. 1995. Determination of trace elements in sea water by ion chromatography-inductively coupled plasma mass spectrometry. Journal of Chromatography A, 709(2): 275-281, http://dx.doi.org/0021-9673(95)00454-8.

Brudin S S, Shellie R A, Haddad P R et al. 2010. Comprehensive two-dimensional liquid chromatography: Ion chromatography $\times$ reversed-phase liquid chromatography for separation of low-molar-mass organic acids. Journal of Chromatography A, 1217(43): 6 742-6 746, http://dx. doi.org/10.1016/j.chrooma.2010.05.064.

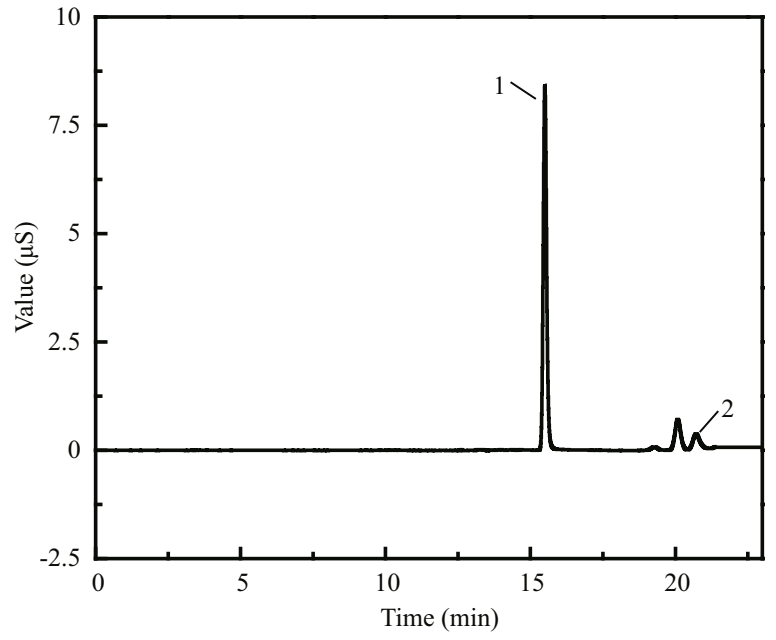

Fig.4 Chromatogram of seawater derived from the valve switching technique

$1=$ chloride; $2=$ nitrate

Bruno P, Caselli M, De Gennaro G et al. 2003. Determination of nutrients in the presence of high chloride concentrations by column-switching ion chromatography. Journal of Chromatography A, 1003(1): 133-141, http://dx.doi.org/ 10.1016/S0304-4203(03)00070-7.

Dahllöf I, Svensson O, Torstensson C. 1997. Optimising the determination of nitrate and phosphate in sea water with ion chromatography using experimental design. Journal of Chromatography A, 771(1): 163-168, http://dx.doi.org/ S002 1-9673(97)00198-2.

Finch M S, Hydes D J, Clayson C H et al. 1998. A low power ultra violet spectrophotometer for measurement of nitrate in seawater: introduction, calibration and initial sea trials. Analytica Chimica Acta, 377(2): 167-177, http://dx.doi. org/1007-1504(2006) 04-0240-06.

Fukushi K, Yamazaki R, Yamane T. 2009. Determination of bromate in highly saline samples using CZE with on-line transient ITP. Journal of Separation Science, 32(3): 457461, http://dx.doi.org/10.1002/jssc.200800502.

Geng X, Zhang S, Wang Q et al. 2008. Determination of organic acids in the presence of inorganic anions by ion chromatography with suppressed conductivity detection. Journal of Chromatography A, 1192(1): 187-190, http:// dx.doi.org/10.1016/j.chroma.2008.03.073.

Gros N. 2013. Ion chromatographic analyses of sea waters, brines and related samples. Water, 5(2): 659-676, http:// dx.doi.org/10.3390/w5020659.

Haddad P R, Nesterenko P N, Buchberger W. 2008. Recent developments and emerging directions in ion chromatography. Journal of Chromatography A, 1184(1): 456-473,http://dx.doi.org/10.1016/j.chroma.2007.10.022. 
Haddad R P, McTaggart A R. 1991. On-column matrix elimination of high levels of chloride and sulfate in nonsuppressed ion chromatography. Journal of Chromatography A, 546: 221-228, http://dx.doi.org/10. 1016/S0021-9673(01)93020-1.

Helaleh M I, Korenaga T. 2000. Ion chromatographic method for simultaneous determination of nitrate and nitrite in human saliva. Journal of Chromatography B: Biomedical Sciences and Applications, 744(2): 433-437, http://dx.doi. org/S0378-4347(00)00264-4.

Huang Y, Mou S F, Liu K N et al. 2000. Simplified columnswitching technology for the determination of traces of anions in the presence of high concentrations of other anions. Journal of Chromatography A, 884(1): 53-59, http://dx.doi.org/10.1016/S0021-9673(00)00319-8.

Ito K, Takayama Y, Makabe $\mathrm{N}$ et al. 2005. Ion chromatography for determination of nitrite and nitrate in seawater using monolithic ODS columns. Journal of Chromatography A, 1083(1): 63-67, http://dx.doi.org/10.1061/j.chroma.2005. 05.073 .

Opiteck G J, Ramirez S M, Jorgenson J W et al. 1998. Comprehensive two-dimensional high-performance liquid chromatography for the isolation of overexpressed proteins and proteome mapping. Analytical Biochemistry, 258(2): 349-361, http://dx.doi.org/0003-2697/98\$25.00.

Raessler M, Hilke I. 2006. Ion-Chromatographic determination of low concentrations of nitrate in solutions of high salinity. Microchimica Acta, 154(1-2): 27-29, http:// dx.doi.org/10.1007/s00604-006-0495-z.

Sastry K, Moudgal R, Mohan J et al. 2002. Spectrophotometric determination of serum nitrite and nitrate by coppercadmium alloy. Analytical Biochemistry, 306(1): 79-82, http://dx.doi.org/10.1006/abio.2002.5676.

Slingsby R, Pohl C. 1996. Approaches to sample preparation for ion chromatography sulfate precipitation on bariumform ion exchangers. Journal of Chromatography A, 739(1): 49-55, http://dx.doi.org/10.1016/0021-9673(96) 00051-9.

Villasenor S R. 1991. Matrix elimination in liquid chromatography using heart-cut column switching techniques. Analytical Chemistry, 63(14): 1 362-1 366, http://dx.doi.org/0003-2700/91/0363-1362\$02.50/0.

Walsh M E. 2001. Determination of nitroaromatic, nitramine, and nitrate ester explosives in soil by gas chromatography and an electron capture detector. Talanta, 54(3): 427-438, http://dx.doi.org/10.1016/S0039-9140(00)00541-5.

Wang R, Wang N, Ye M et al. 2012. Determination of lowlevel anions in seawater by ion chromatography with cycling-column-switching. Journal of Chromatography A, 1265: 186-190, http://dx.doi.org/10.1016/j.chroma. 2012.09.086.

Wang Y, Kong L, Lei X et al. 2009. Comprehensive twodimensional high-performance liquid chromatography system with immobilized liposome chromatography column and reversed-phase column for separation of complex traditional Chinese medicine Longdan Xiegan Decoction. Journal of Chromatography A, 1216(11): 2 185-2 191, http://dx.doi.org/10.1016/j.chroma.2008.05. 074.

Wilson M B, Zhang C C, Gandhi J. 2011. Analysis of inorganic nitrogen and related anions in high salinity water using ion chromatography with tandem UV and conductivity detectors. Journal of Chromatographic Science, 49(8): 596-602.

Zhu Z. 2006. Summarization on investigation headway of determination nitrate and nitrite by spectrophotometry. Arid Environmental Monitoring, 20(4): 240-245, http:// dx.doi.org/1007-1504(2006)04-0240-06. 